\title{
Uso de 2-octil cianoacrilato em anastomose colônica: estudo experimental em ratos wistar
}

\author{
The use of 2-octyl cyanoacrylate in colonic anastomosis: experimental study in \\ wistar rats
}

Cleber Soares Júnior, TCBC-MG ${ }^{1}$; Cláudio de Souza, ACBC-MG²

\section{R E S U M O}

\begin{abstract}
Objetivo: Comparar os resultados das anastomoses colônicas realizadas com o adesivo 2-octil cianoacrilato e as feitas com fio de polipropileno 5.0. Métodos: Selecionaram-se 32 ratos Wistar machos distruibuidos em quatro grupos de oito animais tendo em conta o tipo de sutura - polipropileno ou aplicação de cianoacrilato -, e os dias para eutanásia - terceiro ou sétimo do pós-operatório. Nos animais dos grupos controle, as anastomoses foram realizadas em plano único com fio de polipropileno 5.0. Nos dos grupos com adesivo, elas foram executadas com 2-octil cianoacrilato. Avaliaram-se o tempo operatório, a integridade, o aspecto macroscópico das anastomoses, a pressão de ruptura à distensão, obstrução intestinal, formação de aderências e histologicamente o processo cicatricial e inflamatório. Resultados: O tempo operatório foi significativamente maior nos grupos em que se aplicou adesivo tanto no terceiro quanto no sétimo dias ( $p=0,004)$. A formação de aderências foi mais extensa no grupo 2-octil cianoacrilato estudado no sétimo dia de pós-operatório em comparação com o grupo polipropileno $(p=0,007)$. Os valores obtidos no estudo tensiométrico da anastomose, no sétimo dia de pós-operatório, mostraram-se menores no grupo 2-octil cianoacrilato ( $p=0,002$ ). A frequência de obstrução intestinal parcial foi maior no grupo em que se aplicou adesivo quando avaliado no sétimo dia $(0,029)$. O processo cicatricial e inflamatório não diferiu entre os grupos, seja no terceiro ou sétimo dias ( $p>0,05)$. Conclusão: Em condições experimentais, o uso do 2-octil cianoacrilato, avaliado no sétimo dia revelou-se deletério, levando a intensa formação de aderências, obstrução parcial da luz colônica, e menor resistência mecânica da anastomose.
\end{abstract}

Descritores: Colo. Anastomose. Adesivo.

\section{INTRODUÇÃO}

O s fundamentos da cicatrização colônica têm sido estudados clínica e experimentalmente em virtude da gravidade das deiscências que ocorrem no pós-operatório. A pesquisa de um método seguro para suturas intestinais nos últimos dois séculos levou ao desenvolvimento de diversos materiais e técnicas de anastomoses, além de melhor entendimento do processo cicatricial ${ }^{1,2}$. A contaminação local promove colagenólise, atraso na fibroplasia e na deposição de colágeno, aumentando o risco de extravasamentos s.4. A $^{3,4}$ presença do conteúdo fecal intraluminal promove forças de cisalhamento que interferem no processo de cicatrização, e a ocorrência de distensão local também pode desencadear isquemia na área suturada.

A utilização de adesivos teciduais em substituição ou concomitantemente às suturas intestinais tradicionais, tem obtido atenção dos cirurgiões e pesquisadores, na tentativa de prevenir e reduzir a incidência de complicações anastomóticas.

Adesivos teciduais são substâncias com propriedades químicas de polimerização que formam precipitado sólido após interagir com tecidos vivos. Estes compostos mantêm os tecidos em aposição para permitir a cicatrização de áreas cruentas contíguas e servem de barreira aos extravasamentos ${ }^{5}$. Entre os mais utilizados podemos citar a fibrina e o cianoacrilato.

O uso dos cianoacrilatos mostrou-se insatisfatório no trato gastrointestinal em diversos estudos, determinando alta frequência de vazamento (fístula), indução de processo inflamatório, reação tipo corpo estranho e carcinogênese. Sua utilização isolada determinou mortalidade de $60 \%$ a $97 \%$, em contraposição a $22 \%$ no grupo suturado ${ }^{6,7}$. Entretanto, nenhum destes trabalhos sobre cianocrilatos e sistema digestório foi realizado utilizando-se a formulação mais recente: 2-octil cianoacrilato ${ }^{8}$. Estudos procuraram estabelecer riscos e benefícios deste composto nas suturas colônicas, mas os resultados ainda são discordantes ${ }^{9,10}$

Face à necessidade de aprimoramento dos resultados das anastomoses colônicas, em virtude das complicações e mortalidade que acarretam e, em decorrência do desenvolvimento de novos adesivos teciduais, notadamente o 2-octil cianoacrilato, decidiu-se por pesquisar os resulta-

Trabalho realizado na Universidade Federal de Juiz de Fora, MG, BR.

1. Preceptor da Residência de Cirurgia do Hospital Universitário da Universidade Federal de Juiz de Fora e do Hospital e Maternidade Therezinha de Jesus, Juiz de Fora, MG- BR. 2. Doutor em Cirurgia pela Universidade Federal de Minas Gerais - UFMG - BR. 
dos da aplicação desta nova formulação naquelas anastomoses e comparar os resultados com fio de polipropileno 5.0, pontos separados em plano único extramucoso, no que se refere aos parâmetros tensiométricos (pressão de ruptura à distensão por ar), histológicos (inflamatórios e cicatriciais), mecânico (obstrução da luz intestinal) e quanto à incidência de aderências e o tempo operatório.

\section{MÉTODOS}

Trata-se de um estudo experimental realizado no Centro Biológico da Reprodução, pertencente à Faculdade de Biologia da Universidade Federal de Juiz de Fora, Juiz de Fora, MG, Brasil. A pesquisa foi aprovada pela Comissão de Ética em Pesquisa com Animais desta Instituição (Protocolo $n^{\circ}$ 071/2007-CEEA).

Os animais foram distribuídos aleatoriamente em quatro grupos de oito (P3, C3, P7, C7), de acordo com o tipo de tratamento a ser instituído: polipropileno $(P)$ ou 2octil cianoacrilato (C); e o período de pós-operatório no qual se estabeleceu a data de eutanásia (terceiro ou sétimo dia).

Todos animais incluídos foram machos com peso variando de $251,0 \mathrm{~g}$ a 346,8 g, sendo o peso médio de 291,29 g. A idade variou de 17 a 19 semanas, com média de 18,14 .

Manteve-se jejum pré-operatório de oito horas para alimentos sólidos (ração), e duas horas para água. A tonsura foi realizada na região ventral do animal, após anestesia com ketamina e xilazina.

Após fixação do animal à mesa operatória com os membros em extensão, procedeu-se à anti-sepsia da região abdominal com polivinil-pirrolidona-iodo a $1 \%$ e colocação de campo fenestrado pequeno para isolar a área desinfectada a ser operada. A celiotomia foi realizada por meio de incisão na linha mediana ventral,em extensão de $6 \mathrm{~cm}$, e exteriorização do cólon.

A colotomia foi feita com secção transversal de $100 \%$ da circunferência do cólon $5 \mathrm{~cm}$ distalmente ao ceco, sem abertura do mesocólon, sendo que a hemostasia foi por compressão.

A anastomose colônica nos grupos P3 e P7 foi realizada com pontos simples de fio polipropileno 5.0, plano único extramucoso, sutura invertente. Nos grupos C3 e C7 procedeu-se à anastomose colônica com aplicação de 2-octil cianoacrilato sob a forma de bastão, após aposição dos bordos, em toda área cruenta aposta e até $0,5 \mathrm{~cm}$ lateralmente, após secar com gaze a fim de garantir o contato direto com o tecido. A força mecânica máxima da película adesiva foi admitida quando a substância não estava mais pegajosa. A celiorrafia foi feita em plano único, sutura contínua com fio de poliamida 3.0.

O tempo operatório foi medido desde a incisão na pele até o término da sutura da mesma ao final do procedimento operatório.
Os animais foram submetidos à eutanásia no terceiro ou sétimo dia de pós-operatório para estudo da anastomose. Considerou-se infecção de sítio cirúrgico a presença de secreção purulenta na incisão operatória e/ou no interior da cavidade abdominal, seja na área perianastomótica ou não. A deiscência da sutura intestinal foi considerada presente quando observada secreção entérica no interior do abdome ou abscesso perianastomótico.

A abertura da cavidade abdominal foi cuidadosa, prevenindo lesões de órgãos que porventura estivessem aderidos à parede interna, notadamente à cicatriz da celiotomia. As aderências foram graduadas de acordo com a escala cumulativa descrita por Bothin et al. ${ }^{11}$. Considerou-se, entretanto, que cada alça intestinal aderida ao local da anastomose corresponderia a um ponto, e não apenas o grupamento destas alças.

\section{AVALIAÇÃO DA PRESSÃO DE RUPTURA A DISTENSÃO POR AR}

O cólon foi seccionado $1,5 \mathrm{~cm}$ proximal e distalmente a anastomose, sem que se procedesse à destruição das aderências estabelecidas, para não comprometer o teste de pressão de ruptura à insuflação. A extremidade proximal foi ligada com fio de seda 3.0 e a extremidade distal cateterizada e fixada pelo mesmo fio utilizado anteriormente, de modo a não haver vazamento de ar. O calibre do cateter foi 12 Fr, menor que o diâmetro de secção transversal da alça.

O cateter foi conectado ao manômetro de baixa pressão, e a peça ressecada imergida no recipiente de vidro transparente com água cristalina, em profundidade de $5 \mathrm{~cm}$ a $10 \mathrm{~cm}$ a partir da superfície. A insuflação de ar foi lenta, com elevação da pressão na luz colônica de dois em dois centímetros de água a cada dois segundos, até que houvesse aparecimento de bolhas de ar indicando ruptura da anastomose. Neste momento a pressão foi verificada e registrada.

\section{TESTINAL}

AVALIAÇÃO DA OBSTRUÇÃO DA LUZ IN-

Após teste de ruptura, procedeu-se à cateterização da peça com cateteres de diferentes calibres: $8 \mathrm{Fr}, 10 \mathrm{Fr}, 12 \mathrm{Fr}$ e $14 \mathrm{Fr}$. O cateter de diâmetro $14 \mathrm{Fr}$ correspondeu ao que preencheu toda a luz do órgão quando testado durante a primeira operação, e por isso foi escoIhido como limite de avaliação.

Anotaram-se todos os casos em que não foi possível a passagem de algum dos cateteres através da anastomose, considerando-os como obstrução parcial; ou total, quando nenhum cateter era capaz de ultrapassar a anastomose. Quando os quatro cateteres eram introduzidos e ultrapassavam o local anastomosado, determinou-se ausência de obstrução.

\section{ANÁLISE HISTOLÓGICA}

O segmento colônico utilizado nas análises anteriores foi enviado para estudo histológico. O material foi 
fixado em solução de formalina tamponada a 10\%, por cerca de 24 horas, e, posteriormente, processado em padrão habitual para estudo histológico no Laboratório de Patologia (CiDAP) do Hospital Monte Sinai / Juiz de Fora (MG). Após microtomia com 4ìm de espessura, os cortes histológicos foram submetidos à coloração de picrosiriusred F3BA e hematoxilina-eosina $(\mathrm{HE})$.

A análise histológica foi realizada em microscópio binocular NIKON Eclipse ${ }^{\circledR}$ E400, por patologista sem que este soubesse a que animal (ou grupo) pertencia a peça em estudo. Utilizou-se objetiva com aumento de 4x e ocular com aumento de 10x para a gradação da neoformação conjuntivo-vascular, proliferação fibroblástica, deposição de colágeno, intensidade de processo inflamatório, além da avaliação da presença de re-epitelização e hipertrofia muscular. Utilizou-se objetiva com aumento de 40x e ocular com aumento de 10x para estudo do padrão celular do infiltrado inflamatório.

A deposição de colágeno foi graduada como ausente, quando não observada; discreta, quando as fibras estavam distribuídas esparsamente, em pequena quantidade ao redor de fibroblastos; moderada, quando havia feixes de fibras espessas intercaladas com tecido conjuntivo frouxo; intensa, quando havia grande quantidade de fibras colágenas espessas e compactas depositadas, sem áreas de tecido conjuntivo frouxo ${ }^{12,9,13}$.

A proliferação fibroblástica foi classificada como ausente quando não observada; discreta quando se observaram fibroblastos esparsos, em meio a tecido conjuntivo frouxo; moderada quando os fibroblastos constituíam pequenos feixes multidirecionais; intensa quando os fibroblastos formavam feixes compactos 12,9,13.

A neoformação conjuntivo-vascular foi graduada como discreta nos casos em que se observavam vasos sanguíneos de forma esparsa, com áreas livres entremeadas (até 10 vasos por campo); moderada, quando havia 12 a 15 vasos por campo e intensa, quando ultrapassava este valor ${ }^{12,9,13}$.

Graduou-se a intensidade de processo inflamatório segundo a escala numérica de Ehrlich e Hunt modificada ${ }^{12,9,13}$ : 0, sem evidência; 1, evidência discreta, células distribuidas de forma esparsa, com grandes áreas livres; 2 , evidência moderada, células constituindo agregados densos, mas ainda com áreas livres; 3, evidência intensa, agregados celulares densos e contínuos, sem áreas livres.

O padrão do infiltrado ainda foi classificado por camada (mucosa, submucosa, muscular e serosa) de acordo com o tipo celular em: linfoplasmocitário e/ou granulocítico e/ou neutrofílico. A avaliação microscópica da re-epitelização e da hipertrofia muscular foi dicotômica: presente ou ausente.

Na análise estatística pelo teste de Mann-Whitney foi utilizado para comparação de dois grupos independentes: peso, idade, dose anestésica, tempo operatório, índice de aderências e valor da pressão de ruptura à distensão por ar. O teste exato de Fisher foi empregado para análise de variáveis dicotômicas quando as amostras eram pequenas: presença de obstrução e toda avaliação microscópica (inte- gridade mucosa, neoformação conjuntivo-vascular, deposição de colágeno, proliferação fibroblástica, intensidade do processo inflamatório, padrão celular do infiltrado inflamatório e hipertrofia muscular). O nível de significância adotado para ambos os testes foi de $5 \%(p=0,05)$.

\section{RESULTADOS}

A mortalidade foi de 6,6\% (dois animais). Em ambos casos não foram encontradas as causas da morte durante necropsia. Um animal pertencente ao grupo P7 morreu no quinto dia, e foi excluído do estudo. O rato pertencente ao grupo P7 morreu no sétimo dia de pós-operatório sendo analisados os dados auferidos da análise histológica.

\section{TEMPO OPERATÓRIO}

O tempo operatório variou de 21 minutos a 52 minutos. Análise estatística mostrou que nas operações em que se utilizou o adesivo de 2-octil cianoacrilato os tempos medidos foram estatisticamente superiores àqueles nos quais se utilizou a sutura de polipropileno quando comparados os grupos C3 e P3 $(p=0,04)$ e os grupos C7 e P7 $(p=0,04)$ (Figura 1).

\section{AVALIAÇÃO MACROSCÓPICA DA CAVI- DADE ABDOMINAL}

Não foram encontrados abscessos perianastomóticos ou em outra localização, nem líquido livre em cavidade ou secreção em parede abdominal. Um animal (Grupo C7) apresentou deiscência da parede abdominal com evisceração. A parede abdominal foi ressuturada e o animal evoluiu sem intercorrências.

\section{OBSTRUÇÃO DA LUZ COLÔNICA}

Não ocorreu obstrução colônica completa em nenhum animal. A comparação entre os grupos P3 e C3

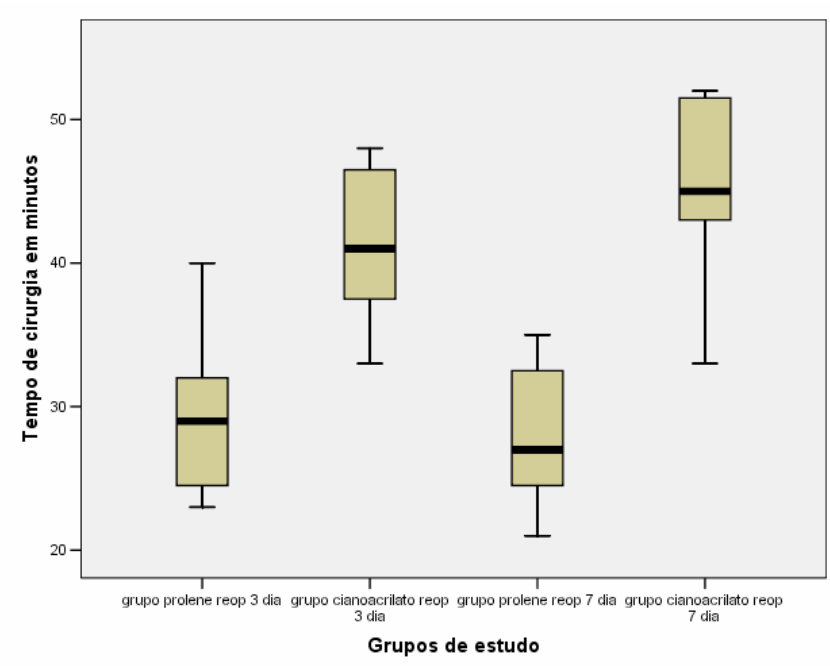

Figura 1 - Comparação entre os tempos operatórios nos quatro grupos estudados. 
não mostrou significância quando aplicado teste exato de Fisher para avaliação da presença de obstrução parcial ( $p=$ $0,315)$. Entretanto, quando analisados os animais necropsiados no sétimo dia (Grupos P7 e C7), observou-se maior frequência de obstrução parcial no grupo em que se aplicou o adesivo ( $p=0,029)$.

\section{ADERENCIAS}

Quando se comparou a presença de aderências entre os grupos polipropileno e 2-octil cianoacrilato, reoperados no $3^{\circ}$ dia, não foi encontrada diferença significativa no teste de Mann-Whitney $(p=0,272)$. De outra forma, quando comparados os índices de aderências entre os grupos P7 e C7 o teste de Mann-Whitney determinou $\mathrm{p}$ = 0,007, com maior quantidade de aderências no grupo 2 octil cianoacrilato (Figura 2).

\section{AR}

\section{PRESSÃO DE RUPTURA A DISTENSÃO POR}

A diferença dos valores médios das médias dos valores das pressões de ruptura à distensão por ar (PRDA) dos grupos polipropileno e cianoacrilato, submetidos à eutanásia no terceiro dia, não foi significativa quando aplicado o teste de Mann-Whitney $(p=0,081)$.

Entretanto, quando esta avaliação foi feita nos grupos polipropileno e cianoacrilato submetidos à eutanásia no sétimo dia, observou-se pressão de ruptura menor no grupo em que se aplicou adesivo ( $p=0,002)$ (Figura 3).

\section{ANÁLISE HISTOLÓGICA}

Na avaliação microscópica, a comparação entre os grupos P3 e C 3 não houve diferença estatística ( $p=1,00)$; a comparação entre os grupos P7 e C7 também não mostrou significância estatística com $p=0,07$. Comparando-se os grupos P3 e C3, e os grupos P7 e C7, não houve diferença estatística em relação à hipertrofia muscular, com $p=$ 0,569 e $p=0,592$ respectivamente. Não houve diferença estatística na neoformação vascular quando comparados os grupos polipropileno e cianoacrilato, com $p=0,315$ para os animais reoperados no terceiro dia, e $p=0,143$ para os reoperados no sétimo dia. Na deposição de colágeno a distribuição de casos nos grupos P3 e C3 foi muito semeIhante; a comparação dos grupos P7 e C7 não mostrou diferença estatística $(p=0,182)$. Quanto à proliferação fibroblástica nenhuma diferença estatística foi encontrada; a comparação entre os grupos P3 e C3 e grupos P7 e C7 mostrou p igual a 1,00 em ambas análises. Na avaliação microscópica do processo inflamatório dos grupos polipropileno e cianoacrilato, no $3^{\circ}$ dia de pós-operatório, observou-se predomínio de processo inflamatório moderado ( $p>0,05)$; o grupo P7 apresentou predominância de processo inflamatório intenso, enquanto o grupo C7 apresentou distribuição homogênea nos graus discreto, moderado e intenso; excluindo-se os casos moderados, e comparando os casos discretos e intensos dos grupos P7 e C7, também não se obteve diferença estatística $(p=0,182)$. Em relação aos tipos celulares do processo inflamatório, na avaliação do infiltrado inflamatório, a distribuição do tipo celu-

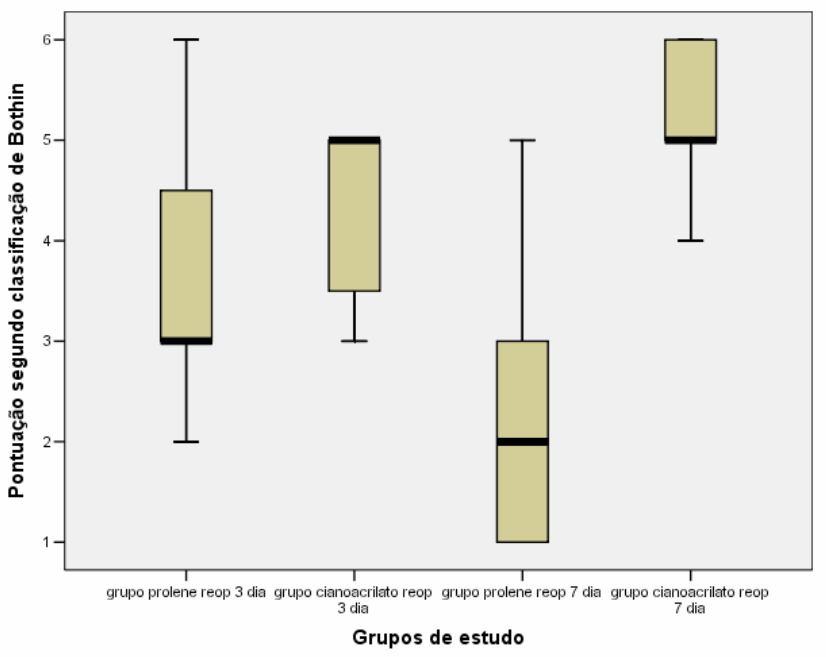

Figura 2 - Comparação da intensidade de aderências entre os grupos estudados segundo a classificação de Bothin et al $(x x X)$.

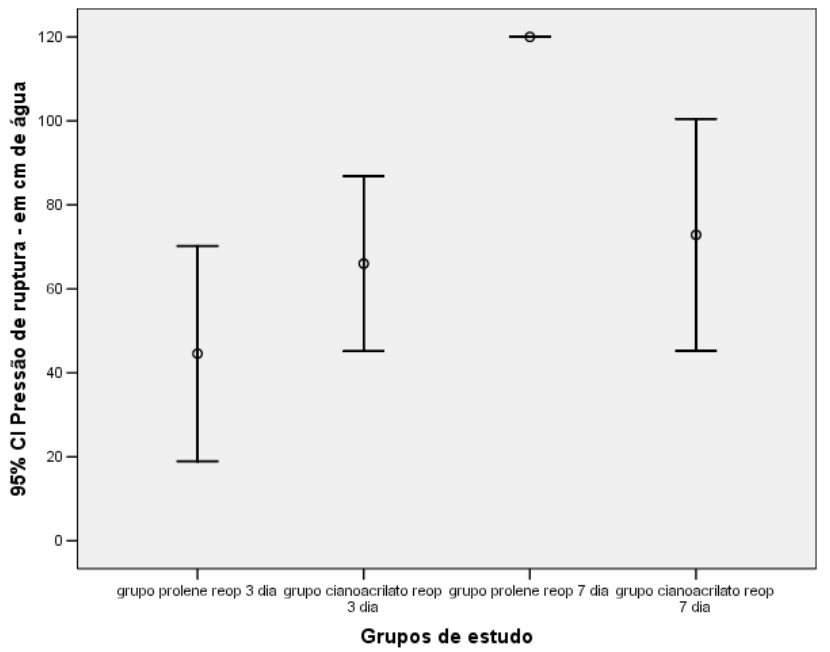

Figura 3 - Comparação dos valores da pressão de ruptura à distensão por ar entre os grupos estudados.

lar nas camadas mucosa, submucosa e serosa não obteve significância estatística quando comparados os grupos C3 e P3, e também os grupos C7 e P7 ( $>>0,05)$.

\section{DISCUSSÃO}

Os cianoacrilatos constituem-se em grupo de adesivos de polimerização rápida, parcialmente degradáveis, que têm sido cada vez mais utilizados em cirurgia. O contato com íons hidroxila, após sua aplicação em tecidos vivos, promove uma reação de hidroxilação exotérmica que polimeriza o composto e o endurece ${ }^{14}$.

A etiologia da toxicidade tecidual destas substâncias é atribuída aos seus produtos de degradação (cianoacetato, formaldeído e hidroperóxidos), que ativam a síntese de prostaglandinas e tromboxanos, participantes da oxidação e lise da membrana celular ${ }^{15-17}$. 
Os cianoacrilatos apresentam propriedades antibacterianas podendo reduzir a incidência de infecções por organismos gram-positivos e alguns gram-negativos quando comparados à sutura com fio monofilamentar $8,14,18-20$.

O 2-octil cianoacrilato apresenta ultra-estrutura três vezes mais resistente que seu antecessor, o butil- 2 cianoacrilato, com degradação lenta que permite a formação de composto mais forte, com menor desenvolvimento de metabólitos, menor concentração local destas substâncias, e menor reação tecidual ${ }^{8,16-18,21}$.

A escolha dos dias de pós-operatório para eutanásia dos animais (terceiro e sétimo dias) baseou-se vários estudos estudos ${ }^{1,22-24}$. Estes autores concluíram em seus trabalhos que a maioria das complicações na anastomose ocorre até o sétimo dia de pós-operatório e que, após este período, a medida de pressão de ruptura da anastomose se assemelha ao tecido intacto, o que limita a análise deste parâmetro $^{4,7}$

Em relação ao tempo operatório, foi significativamente mais longo nos animais submetidos à aplicação de 2-octil cianoacrilato $(p=0,004)$. Este fato não é consistente com outros trabalhos da literatura, que mostram que a aplicação de adesivo demanda tempo mais curto do que a sutura ${ }^{5,8,25}$. Isto talvez possa ser atribuído à necessidade de hemostasia rigorosa para aplicação do adesivo, e a não utilização do eletrocautério, o que determinou tempo maior de compressão hemostática.

No presente estudo utilizou-se para sutura o fio de polipropileno 5.0, conquanto Singer e Thode ${ }^{8}$ afirmaram que a ultraestrutura do 2-octil cianoacrilato tem resistência que se assemelha à de um monofilamento 5.0, diferentemente de Kanellos et al. e Nursal et al. ${ }^{9,10}$ que utilizaram fios de polipropileno 6.0 e 7.0 respectivamente. No que se refere ao adesivo, não foram aplicados pontos de reparo ou suporte antes de sua aplicação, o que contrasta com outros trabalhos que investigaram a utilização de adesivos nas anastomoses intestinais e pontos de suporte antes da aplicação do adesivo.

Estas modificações técnicas podem ter interferido nos resultados: a incidência de complicações tipo infecção de sítio cirúrgico superficial e profundo no presente estudo foi de $0 \%$, bastante inferior quando comparado aos outros da literatura. Nursal et al. ${ }^{10}$ comparando o efeito do 2-octil cianoacrilato na cicatrização colônica, obtiveram sete casos de infecção de ferida cirúrgica (quatro em anastomose com cianoacrilato), mas sem diferença significante $(p=0,297)$, identificou dois abscessos perianastomóticos e duas deiscências, também sem significância em relação ao grupo controle. A ocorrência destes abscessos foi atribuída a vazamentos perianastomóticos posteriormente tamponados. Kanellos et al. ${ }^{9}$ apresentaram incidência de $20 \%$ de peritonite no mesmo tipo de estudo com anastomose colônica e 2-octil cianoacrilato. Entretanto, no estudo de Amaral et al. ${ }^{15}$, no grupo em que se aplicou cianoacrilato sobre enterorrafias a incidência de complicações infecciosas perianastomóticas não foi significativamente superior.

\section{AVALIAÇÃO DE ADERÊNCIAS}

As aderências podem alterar a reparação tecidual da linha de sutura e seus efeitos benéficos incluem ações protetoras biológicas - neovascularização, melhoria do processo de drenagem linfática e capacitação fagocitária, e mecânicas - oclusão de falhas anastomóticas. Wu et al. ${ }^{25}$, em estudo experimental, mostraram que nos subgrupos em que não ocorreu aderência sobre as anastomoses foram encontrados menores valores de resistência mecânica devido à falta da proteção biológica e mecânica.

O presente estudo optou por utilizar a escala cumulativa de Bothin, aplicada em outros trabalhos. Este escore apresenta especificidades em relação aos ratos, tendo sido primariamente criado para pesquisa nestes animais. Para cada aderência encontrada soma-se um ponto e ao final têm-se um valor que corresponde não somente à intensidade das aderências, mas também à quantidade delas. Esta classificação foi validada em outro estudo ${ }^{11}$.

Os resultados aqui obtidos foram corroborados por autores que estudaram a influência dos outros tipos de cianoacrilatos na cicatrização do TGI, e mostram intensidade maior de aderências na utilização destas substâncias quando comparadas com a sutura tradicional 6,7, 15, 26,27.

No trabalho de Kanellos et al. ${ }^{9}$ todos os animais do grupo tratado com 2-octil cianoacrilato apresentaram incidência moderada ou grave de aderências abdominais, apesar de não haver diferença estatística $(p=0,074)$. Comparando a aplicação de 2-octil cianoacrilato com a aplicação de fibrina sobre anastomoses intestinais, Amaral et al. ${ }^{15}$ observou incidência maior de aderências no grupo com adesivo sintético.

\section{OBSTRUÇÃO DA LUZ COLÓNICA}

Estudo de Nursal et a/ ${ }^{10}$ não mostrou diferença no que se refere à ocorrência de obstrução no pós-operatório de anastomose colônicas comparando suturas de polipropileno e adesivos de cianoacrilato. Isto se deve ao fato do autor ter apenas avaliado a presença de obstruções completas e por meio de estudo macroscópico (diâmetro do segmento intestinal à montante da anastomose, duas vezes maior que aquele à jusante). Isto se contrapõe aos resultados do presente estudo no qual se observou diferença comparando-se os grupos polipropileno e 2octil cianoacrilato avaliados no sétimo dia ( $p=0,029)$, sugerindo que a presença de cianoacrilato induz a persistência de processo inflamatório e pode levar a estenose do órgão.

Amaral et al. ${ }^{15}$, estudando anastomoses intestinais, obtiveram incidência maior de estenose no grupo tratado com 2-octil cianoacrilato quando comparado com o grupo em que foi aplicado adesivo de fibrina. Resultados semelhantes foram obtidos por Souza ${ }^{7}$ estudando o efeito do adesivo de glutaraldeído-resorcinol-formaldeído (GRF) em anastomoses colônicas em ratos. A incidência de semi-obstrução nos grupos com adesivo GRF foi maior que nos grupos suturados ou em que se aplicou fibrina. 


\section{PARÂMETROS TENSIOMÉTRICOS}

A resistência da anastomose corresponde ao resultado da ação das propriedades cicatriciais do tecido em reparação ${ }^{27,28}$. Neste experimento, a medida da pressão de ruptura à distensão (PRDA) foi escolhida como parâmetro mecânico da avaliação da anastomose. Segundo Heibel et al. ${ }^{13}$, um bom estudo tensiométrico deve levar em consideração os tipos de forças naturais a que está exposto o tecido em questão. A pressão de ruptura à distensão representa a força exercida pela pressão intraluminal que seria a que naturalmente atua sobre as suturas intestinais. Quando a análise se relaciona à víscera oca, o teste de resistência à insuflação de ar pode ser considerado como mais fisiológico, por reproduzir os vetores de força que normalmente se transmitem sobre a parede do trato digestório. Outra vantagem deste tipo de teste é que ele aplica pressão em toda circunferência interna do órgão, submetendo-o simultaneamente a uma prova de vedação. Este estudo tensiométrico tem sido utilizado consistentemente na literatura para este tipo de investigação 2, 9, 10, 13 .

A pressão de ruptura à distensão por ar (PRDA) tem seus menores valores durante o segundo e terceiro dias de pós-operatório, alcançando queda de 15\% quando comparado com o pós-operatório imediato; após, aumenta progressivamente. Segundo Trubian ${ }^{28}$, as anastomoses colônicas perdem $72 \%-95 \%$ de sua força de ruptura nos três primeiros dias de pós-operatório. Uma semana após a operação, esta resistência à distensão por parte da anastomose é similar àquela dos controles não operados ${ }^{28}$.

Dois estudos avaliaram os resultados da mensuração da PRDA nas anastomoses colônicas após aplicação de 2-octil cianoacrilato, comparando com sutura de polipropileno. Kanellos et al. ${ }^{9}$ não obtiveram diferença quando compararam os grupos ( $p=0,897)$ e concluíram que, em condições experimentais, uma anastomose sem sutura (com cianoacrilato) é igual à tradicional (fio de polipropileno). Nursal et al. 10, ao contrário, enfatizaram que o 2-octil cianoacrilato parece ser deletério à cicatrização em uma fase tardia, provavelmente devido à intensa reação inflamatória que provoca. Estes autores não encontraram diferenças no estudo tensiométrico, quando as peças cirúrgicas foram analisadas no terceiro dia, apesar de os valores de todo grupo com adesivo serem menores que do grupo controle. A análise das peças no sétimo dia é nitidamente diferente, com valores do grupo cianoacrilato inferiores ao do grupo controle $(p<0,001)$. Resultados similares foram encontrados no presente estudo no qual a aplicação do 2octil cianoacrilato mostrou que a resistência à pressão de ruptura por distensão, no sétimo dia de pós-operatório, foi significativamente menor.

\section{ANÁLISE HISTOLOGGICA}

O grau de intensidade do processo inflamatório é fundamental na evolução da cicatrização ${ }^{13}$. Reação Inflamatória leve a moderada é essencial e fisiológica. Entretanto, reação intensa pode comprometer a cicatrização por distúrbio na microcirculação. No presente estudo não foi encontrada diferença quando se compararam os grupos polipropileno e cianoacrilato no terceiro e sétimo dias, no que refere à intensidade do processo inflamatório. Isto pode se dever ao pequeno tamanho da amostra e se contrapõe aos resultados de Nursal et al. ${ }^{10}$ em que se observou incidência maior de infiltrado granulocítico e menor de infiltrado mononuclear nos animais submetidos à aplicação de 2-octil cianoacrilato estudados no terceiro dia de pós-operatório. Estes autores também observaram que o padrão celular no sétimo dia mostrou maior incidência de infiltração granulocítica nos grupos submetidos à aplicação do adesivo.

Não ocorreu necrose no sítio anastomótico em nenhum animal do presente estudo. Outras pesquisas mostraram incidência maior desta alteração nos grupos submetidos à anastomose com adesivo ${ }^{10}$. Isto pode se dever a isquemia da borda, conquanto nos trabalhos da literatura houve aplicação de pontos de reparo previamente a aplicação do adesivo. Este tipo de procedimento não é imprescindível à execução da anastomose. Wilker et al. ${ }^{29}$ mostraram que anastomoses sem sutura, apenas por aproximação, tendem a apresentar menor incidência de necrose; isto pode ter contribuído para os resultados desta pesquisa, mesmo levando-se em conta que a degradação do cianoacrilato leva ao acúmulo de cianoacetato e formaldeído, tóxicos ao tecido circunjacente.

Na avaliação da fibroplasia, deposição de colágeno e neoformação conjuntivo-vascular não houve diferença entre os quatro grupos estudados. Em contrapartida no estudo de Nursal et al. ${ }^{10}$ houve menos fibroplasia nos grupos com adesivo avaliados no terceiro dia de pós-operatório ( $p<0,001)$. Entretanto, os resultados deste autor quanto à angiogênese foram iguais a este estudo, comparando-se os grupos cianoacrilato com controle $(p>0,05)$.

Amaral et al. ${ }^{15}$ concluiram que o adesivo biológico estimulou mais a formação de fibras colágenas do que o adesivo sintético.

Em condições experimentais, o uso do 2-octil cianoacrilato, avaliado no terceiro dia, não apresentou vantagens em relação à anastomose convencional. Quando avaliado no sétimo dia, o adesivo revelou-se deletério, levando a intensa formação de aderências, obstrução parcial da luz colônica, e interferência na cicatrização com menor resistência mecânica à pressão de ruptura.

Em decorrência do tamanho da amostra e dos resultados obtidos, novos trabalhos devem ser realizados com a intenção de elucidar melhor a influência do 2-octil cianoacrilato nas anastomoses intestinais, notadamente a anastomose colônica. Faz-se necessário aprimoramento do entendimento das alterações inflamatórias e cicatriciais nos tecidos colônicos após aplicação do adesivo em questão.

Em conclusão, em condições experimentais, o uso do 2-octil cianoacrilato, avaliado no sétimo dia revelou-se deletério, levando à intensa formação de aderências, obstrução parcial da luz colônica e menor resistência mecânica da anastomose. 


\title{
A B S T R A C T
}

\begin{abstract}
Objective: To compare the effect of 2-octyl cyanoacrylate tissue adhesive with polypropylene suture on the healing of colonic anastomosis in Wistar rats. Methods: Thirty two animals, divided in four groups of eigth, were established concerning suture with Polypropylene or Cyanoacrylate application, and the day chose for euthanasia: third or seventh day following operation. In the control group, the anastomosis was done in a single layer with 5.0 polypropylene suture. In the adhesive group, the anastomosis was performed by using 2-octyl cyanoacrylate. Operative time, integrity and gross anastomotic healing, bursting pressure, intestinal obstruction, adhesions formation, histological healing and inflammatory process were recorded. Results: Adhesion formation was more extensive in the cyanoacrylate group on the seventh postoperative day comparing with suture group ( $p=0.007)$. Mechanical strength of the anastomosis assessed on the seventh postoperative day was lower in 2-octyl cyanoacrylate group $(p=0.002)$. Partial intestinal obstruction rate were more frequent in anastomosis using 2-octyl cyanoacrylate compared to those with polypropylene suture on the seventh postoperative day $(p=0.029)$. Operative time were longer in groups with adhesive $(p=0.004)$. The wound healing process, and inflammatory process did not differ statistically between groups ( $p>0.05)$. Conclusion: The application of 2-octyl cyanoacrylate, under experimental conditions seems to be detrimental at the seventh day of the healing, causing intense adhesion formation, colonic obstruction; and impairment healing with less mechanical strength resistance.
\end{abstract}

Key words: Colon. Anastomosis. Adhesive.

\section{REFERÊNCIAS}

1. Kanto R, Fagundes DJ. Estudo morfológico comparativo de anastomoses colônicas por invaginação versus em plano único extra-mucoso em cães. Rev Bras Coloproct. 2005; 25(1):51-9.

2. Mantzoros I, Kanellos I, Demetriades H, Christoforidis E, Kanellos D, Pramateftakis MG, Zaraboukas T, Betsis D. Effects of steroid on the healing of colonic anastomoses in the rat. Tech. Coloproctol. 2004; 8(1): s180-3.

3. Orlando MD, Chendrasekhar A, Bundz. The effect of peritoneal contamination on wound strength of small and colonic anastomosis. Am. Surg. 1999; 65(7):673-5; discussion 676.

4. Zabel DD, Hunt TK, Mueller RV, Goodson WH. Wound Healing In: Way LW, Doherty GM. current surgical diagnosis \& treatment. $11^{\text {th }}$ edition. Lange Medical Books/McGraw-Hill; 2003.

5. Reece TB, Maxey TS, Kron IL. A prospectus on tissue adhesives. Am J Surg. 2001; 182(2):40S-4S.

6. Nordkild P, Hjortrup A, Kierkegaard J. Tissue adhesives and intestinal anastomosis. Ann Chir. 1986; 75:205-8.

7. Souza C. Uso de adesivos biológicos em anastomoses intestinais Estudo experimental em coelhos [tdissertação]. Belo Horizonte (MG): Faculdade de Medicina, Universidade Federal de Minas Gerais; 1993.

8. Singer AJ, Thode HC. A review of the literature on octylcyanoacrylate tissue adhesive. Am J Surg. 2004; 187(2):238-48.

9. Kanellos I, Mantzoros I, Demetriades H, Kalfadis S, Sakkas L, Kelpis $\mathrm{T}$, Betsis D. Sutureless colonic anastomosis in the rat: a randomized controlled study. Tech Coloproctol. 2002; 6(1):146.

10. Nursal TZ, Anarat R, Bircan S, Yildirim S, Tarim A, Haberal M. The effect of tissue adhesive, octyl-cyanoacrylate, on the healing of experimental high-risk and normal colonic anastomoses. Am J Surg. 2004; 187(1):28-32.

11. Bothin C, Okada M, Midvedt T. Postsurgical adhesion formation in germfree and ex-germfree rats - a study using three scoring scales. J. Invest Surg. 1999; 12(1):147-50.

12. Phillips JD, Kim CS, Fonkalsrud EW, Zeng H, Dindar H. Effects of chronic corticosteroids and vitamin A on the healing of intestinal anastomoses. Am J Surg. 1992; 163(1):71-7.

13. Heibel M, Dietz UA, Malafaia O, Czeczko NG, Araújo UR, Inácio CM. Influência do Alprostadil na cicatrização da anastomose de esôfago cervical - estudo em cães. Arq Bras Cir Dig. 2006; 19(4):123-32.

14. Quinn J, Maw J, Ramotar K. Octylcyanoacrylate tissue adhesive versus suture wound repair in a contaminated wound model. Surgery. 1997; 122(1):69-72.

15. Amaral AT, Taha, MO, Fagundes DJ, Simões MJ, Novo NF, Juliano Y. Estudo morfológico das entero-anastomoses com suturas em pontos separados complementados com adesivo sintético ou biológico em coelho. Acta Cir Bras. 2004; 19(4):393-405.

16. Haber GB. Tissue glue for pancreatic fistula. Gastrointest Endosc. 2004; 59(4):535-7.

17. Bahten LC, Noronha L, Silveira F, Nicollelli G, Longhi P, Pantanali CAR. Estudo da cicatrização nas lesões traumáticas esplênicas utilizando octil-2 cianoacrilato e fio de poliglecaprone. Rev Col Bras Cir. 2006; 33(3): 174-80.

18. Narang U, Mainwaring L, Spath G, Barefoot J. In-vitro analysis for microbial barrier properties of 2-octyl cyanoacrylate-derived wound treatment films. J Cutan Med Surg. 2003; 7(1):13-9.

19. Howell JM, Bresnahan KA, Stair TO. A comparison of effects of suture and cyanoacrylate tissue adhesive on bacterial counts in contaminated lacerations. Antimicrobial Agents and Chemotherapy. 1995; 39(2):559-60.

20. Singer AJ, Thode HC, McClain S. The effects of octylcyanoacrylate on scarring after burns. Acad Emerg Med. 2001; 8(2):107-11.

21. Nitsch A, Pabyk A, Honig JF, Verheggen R, Merten HA. Cellular, histomorphologic, and clinical characteristics of a new octyl-2cyanoacrylate skin adhesive. Aesthetic Plast Surg. 2005; 29(1):538. Epub 2005 Mar 11

22. Jiborn $\mathrm{H}$, Ahonen J, Zederfeldt $\mathrm{B}$. Bursting strength of the colon after left colon resection and anastomosis. Am J Surg. 1978; 136(5):587-94.

23. Jiborn $\mathrm{H}$, Ahonen J, Zederfeldt B. Healing of experimental colonic anastomosis. Effect of suture technique on collagen concentration in the colonic wall. Am. J. Surg. 1978; 135(3):333-40.

24. Hendricks T, Mastboom WJB. Healing of experimental intestinal anastomosis: parameters of repair. Dis. Colon Rectum. 1990; 33(10):891-901.

25. Wu FC, Ayrizono MLS, Fagundes, JJ, Coy CSR, Góes JRN, Leonardi LS. Estudos biomecânicos da ação de aderências sobre anastomose cólica. Trabalho experimental em ratos. Acta Cir Bras; 2003; 18(3):216-23.

26. Sousa TFC, Silva AL. Estudo experimental das entero-anastomoses com o 2-metil-cianoacrilato, em cobaias. Acta Cir Bras. 1988; 391):80-8.

27. Naresse LE, Lucchiari PH, Angeleti AYO, Burini RC, Rodrigues MAM, Curi PR, Kobayashi S. Estudo comparativo de anastomoses no intestino delgado de cão: estudos da força de ruptura, hidroxiprolina tecidual e anatomopatológico. Acta Cir Bras. 1988; 3(4):106-12.

28. Trubian PS. Influência do octreotide na cicatrização de sutura gástrica em ratos: estudo tensiométrico e da morfologia do colágeno [dissertação]. Curitiba (PR): Universidade Federal do Paraná; 2004

29. Wilker D, Sklarek J, Waldner H, Posel P. Nahtfreie anastomosen an dr Ratte, am kaninchen und am Schwein. Langenbecks Arch Chir. 1988; 737(1):91-6. 
Recebido em 06/02/2009

Aceito para publicação em 09/04/2009

Conflito de interesse:nenhum

Fonte de financiamento: nenuma

\section{Como citar esse artigo:}

Soares Júnior C, Souza C. Uso de 2-octil cianoacrilato em anastomose colônica: estudo experimental em ratos wistar. Rev Col Bras Cir. [periódico na Internet] 2010; 37(2). Disponível em URL: http://www.scielo.br/ $\mathrm{rcbc}$

\section{Endereço para correspondência:}

Cleber Soares Júnior

Rua Chanceler Oswaldo Aranha, 82 / apto. 501

Bairro São Mateus, Juiz de Fora, Minas Gerais

CEP: 36016-340

E-mail: cleberdoc@ig.com.br 